\title{
Immunology Today
}

\author{
March 1984
}

\section{Immunotechnology and Industry}

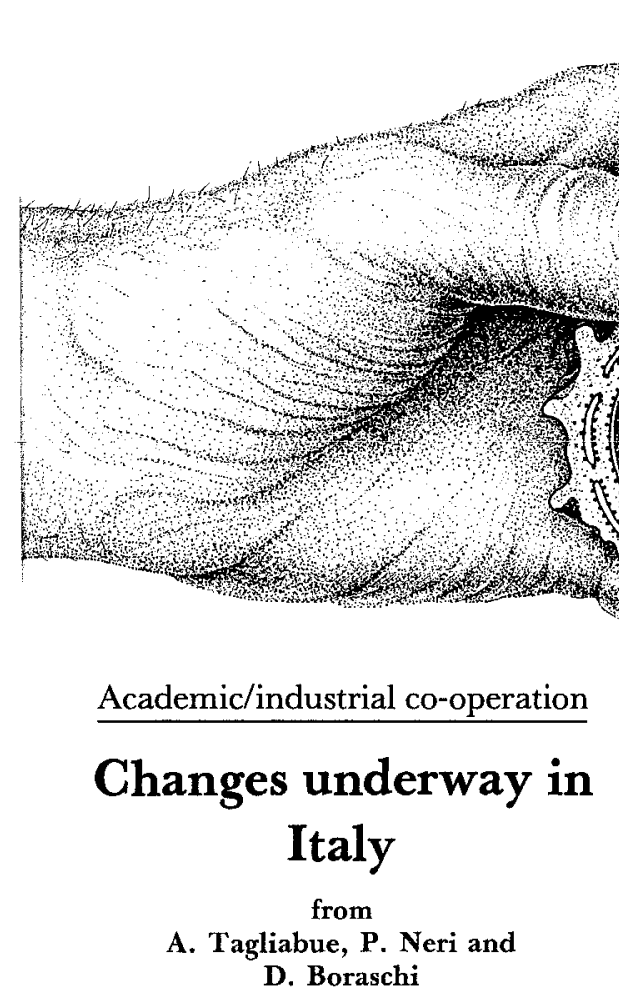

The bite of economic recession, which is particularly harsh in Italy where the inflation rate was $16 \%$ in 1982 and 13$14 \%$ in 1983 , has shaken some of the most traditional and established Italian industrial groups involved in biomedical production, leading them to adopt the promising approach of immunotechnology. At Sclavo, a company of the health branch of the National Corporation for Hydrocarbons (ENI), new research facilities for studying monoclonal antibodies (Mabs) and lymphokines have been established and a new pilot plant for $\beta$-interferon production has been set up. Moreover, in continuation of an 80-year-old tradition at Sclavo, the major Italian producer of vaccines, new programs for research and development of synthetic or recombinant DNA-

\author{
Alternative funding
}

\section{Sponsorship of scientific work}

from

H. F. J. Dullens, R. A. De Weger and $W$. den Otter

In their recent Immunology Today article entitled 'Commercial vision needed in the lab and dogged finance outside it', A. A. van Es and J. J. Haaijman state that governmental funding in the Netherlands is being slowly but steadily reduced and that scientists will have to find alternative sources of funding ${ }^{1}$. Furthermore they quite rightly say that most Dutch scientists do not think commercially and are afraid to become engaged in commercial affairs. Such fear is not always justified. Recently a new form of alternative funding of scientific work has emerged in the Netherlands, namely, sponsoring. The research group in the Department of Experimental Pathology (Faculty of Medicine) of the Rijks Universiteit at Utrecht has succeeded in attracting alternative support from a commercial source, the Algemene Bank Nederland (ABN Bank), one of the largest banking institutions in the Netherlands. The work supported is a study of the functioning of the immune system in tumor-bearing mice.

Although this is still a tentative venvaccines have been started. comitantly, at Farmitalia-Carlo Erba, the pharmaceutical division of Montedison, the major private chemical group in Italy, research is going on in the fields of Mabs, lymphokines and new synthetic immunomodulators. Sorin, which belongs to the automobile company Fiat, is involved in research and development of Mabs for diagnostics; and at Serono, experimental and clinical research is in progress with thymic hormones and $\beta$ interferon.

So far, the general trend in the industrial immunotechnological expansion has been to recruit scientists from Continued on p. 56 ture, the ABN Bank provides the bench fee for an academic for one year; the Bank has no wish to claim or commercially exploit results from the experimental work, nor does it claim influence on the experimental work itself. On the other hand, the ABN Bank is a commercial institution and some form of recognition is required. In return, the investigators acknowledge the Bank's financial support when presenting results of the sponsored work, so contributing to and extending the reputation of the Bank.

$$
\text { Continued on p. } 56
$$


Sponsorship-contd. from p. 55

If this venture proves to be satisfactory to both parties, the Bank and the University may consider continuing or even extending this form of sponsorship.

\section{Reference \\ 1 van Es, A. A. and Haaijman, J. J. (1983) Immunol. Today 4, 131-132}

H. F.J. Dullens, R. A. De Weger and W. Den Otter are in the Department of Experimental Pathology, Rijksuniversiteit Utrecht, $3511 \mathrm{HX}$ Utrecht, The Netherlands.

Changes underway-contd. from $p .55$

academic institutions to the industrial research centers. Industry has only very rarely established collaborative projects for applied research with academic institutions, but owing to the generally poor economic situation quite a number of academicians have been prepared to overcome their traditional suspicion of industry. However, numerous bureaucratic and organizational problems generated by the obsolete laws regulating Italian academic institutions, such as the universities and the National Research Council (CNR), have largely discour- aged industry from financing applied research projects to be conducted in academic institutions. As a typical example, it is impossible at the present time for universities to increase their personnel by hiring the new staff needed to carry out new applied research projects. This problem cannot be solved easily by creating fellowships, because in a country where all jobs offered are on a permanent basis they are much disliked. Thus it is the inflexibility of Italian academic institutions that has the greatest effect on their scientific interactions with industry.

But changes are now underway and the situation may be different in the near future. In 1976 the CNR, whose budget covers almost all the biomedical research of academic institutions, created the progetti finalizzati (literally 'finalized projects', although the meaning is closer to 'goal-oriented projects'), devoting a significant proportion of its budget to applied research programs. Since industrial institutions can also apply for funding within the finalized projects scheme, a bridge has been created between the academic institutions and industry. Indeed two projects, on biomedical technology and on chemistry, are of major interest in the development of immunotechnology.

A further contribution to technological research has been offered by the Italian government which has approved a new law appropriating 1700 billion lira (1.1 billion US dollars) to a 'special fund for applied research'. This is also expected to further encourage the collaboration between academic institutions and industry.

Another result of the government's financial policy in support of applied research in Italy has been that, in an attempt to improve the co-ordination of industrial research, several companies including those interested in immunotechnology have founded two research societies, named Tecnobiomedica, for biomedical research, and Tecnofarmaci, for pharmacological research.

It does not seem too optimistic to hope that the increasing collaboration will shortly generate positive results.

A. Tagliabue and D. Boraschi are in the Laboratory of Immunopharmacology at the Sclavo Research Center; $P$. Neri is in the Department of Chemistry, University of Siena, and is also Research Coordinator within the 'Progetto Finalizzato CNR Chimica Fine e Secondaria'.

\section{Monoclonal antibodies in immunocytology}

\section{A jungle full of pitfalls}

\section{from J. J. Haaijman, G. Deen, C. J. M. Kröse, J. J. Zijlstra, J. Coolen} and J. Radl

A respectable immunologist cannot do without monoclonal antibodies (Mabs). These reagents are specific and amenable to large-scale preparation. Thus they offer the prospect of further standardization, so much needed in diagnostic immunocytology. A major problem with Mabs, however, is that they tend to be highly assay-specific. In other words, they may perform excellently in one assay but give mediocre or even completely negative results in another. This phenomenon haunts investigators who wish to distribute their Mabs through commercial channels.

Although 'assay-specificity' is an accepted commodity in Mab research, very little attention is paid to it in the literature. We would like to illustrate the problem here with data on a particular set of Mabs, namely, mouse antibodies directed against human immunoglobulins (Igs). The antibodies produced in our laboratory are intended for research on the distribution in human tissues of cells containing cytoplasmic $\operatorname{Ig}$ (their frequency and heavy- or light-chain commitment) and for investigations on isotype expression in B cells.
To determine the specificity of our antibodies, we apply them in the following test systems.

Radioimmunoassay (RIA) using a large array of highly purified human paraproteins of various immunoglobulin classes and subclasses. The set includes paraproteins of $\boldsymbol{x}$ and $\lambda$ types, a number of allotypes, as well as Bence-Jones proteins. The target antigens are adsorbed to polyvinyl microtitration plates ${ }^{\text {. }}$ Various dilutions of Mabs either in supernatant or ascitic fluid are applied to individual wells. Bound antibody is quantitated with an iodine-labelled antimouse Ig reagent

Enzyme-linked immunosorbent assay (ELISA) is performed along the same lines as the RIA. Antigens are adsorbed to polystyrene Terasaki plates ${ }^{2}$. A peroxidase-labelled anti-mouse $\mathrm{Ig}$ is used for the detection of bound Mab. We normally use orthophenylene diamine as the substrate for the enzyme reaction. The colour development in individual wells of the Terasaki plates is determined with an inverted microscope equipped with a photometer attachment.
Double immunodiffusion and conventional immunoelectrophoresis to test the precipitation properties of Mabs. Polyethylene glycol (mol. wt 6000 ) at a $3 \%$ concentration is included in the agar to enhance precipitation ${ }^{3}$. Where appropriate, we include target antigens of monomeric and polymeric form (for example, in the IgA system)

Membrane-bound Ig assay with peripheral blood lymphocytes of presumably healthy donors collected by the 'Ficoll' method. Before incubation with Mabs, the cells are mildly treated with a low concentration of formalin to reduce 'non-specific Fc-type' interactions ${ }^{4}$. The binding of Mab is checked directly (using fluorescent conjugates) or indirectly with a fluorescent anti-mouse-Ig as the second-step reagent. The morphology of the fluorescent cells is established with phase-contrast microscopy.

Intracellular Ig assay on cytocentrifuge preparations of bone-marrow cells fixed in acid ethanol, washed and incubated with fluorescent $\mathrm{Mab}^{5}$. The reactivity of different antibodies is compared and contrasted by employing flourescien- and rhodamine-conjugated antibodies and applying them in a two-colour design ${ }^{6}$. The method of immunofluorescence microscopy is particularly suited for working with cells which can be easily brought into suspension. On the other 